\title{
Fóruns Híbridos de Participação: no sentido de melhores práticas para a construção da cidade ${ }^{1}$
}

\author{
Maira Machado-Martins \\ DAU- PPGArq- PUC-Rio. \\ Contato: mmartins.maira@gmail.com \\ Patricia Maya-Monteiro \\ FAU-UFRJ, MPAP-PROURB. \\ Contato: pmmayam@gmail.com
}

\section{RESUMO}

Este trabalho apresenta os resultados de um processo projetual realizado nos baixios de dois viadutos no Bairro de Laranjeiras, na cidade do Rio de Janeiro. Este processo fez parte do projeto de extensão "A praça, a rua e o bairro", conduzido por alunos e docentes de diferentes campos e cursos, que busca mostrar a importância da intervençáo nas cidades através da participação popular de forma direta na elaboração e implementação de propostas urbanas e paisagísticas. Configurou-se um processo colaborativo, buscando incorporar a noção de que há um "saber local, nutrido pelo cotidiano", como propóe Milton Santos (1997, p.7). Traremos aqui o relato da construção metodológica e o processo de experiência projetual no caso de Laranjeiras. Buscamos demonstrar como pode se dar o desenho e construção da cidade através de processos participativos e colaborativos. A presença de um projeto informado e congregador pode constituir um ambiente de debate para que possam ser forjadas soluçóes mais justas e adequadas.

Palavras-chaves: Espaço Público, Processo Colaborativo, Metodologia Participativa

\section{ABSTRACT}

This article presents the results of a Project process held in the under-spaces of two viaducts in the Laranjeiras district in the city of Rio de Janeiro. This process is part of a community-university partnership project, the "Square, the Street and the District", which has been developed by students and professors of different fields and courses. This project aims to emphasize the relevance of interventions in the cities are made by a direct mode of popular participation, both in the elaboration and in the implementation of landscape architecture and urban proposals. A collaborative process was shaped to embody the notion that there is a "local knowledge, which is nurtured by the daily life", as Milton Santos (1997, p.7) argues. Here, we narrate the methodological construction and the process of design experience in this case at the Laranjeiras.district. With this, we expect to demonstrate how the design and building of the city can be developed thorough participative and collaborative processes. The existence of an assembled and well informed project can be an environment to foster discussion so that more just and appropriate solutions may get forge.

Keywords: Public Space, Collaborative Process, Participatory Methodology 


\section{Introduçáo}

Como desenhar a cidade sem (re)produzir o totalitarismo da ordem ou da forma urbana? Como minimizar os efeitos excludentes de muitas das práticas urbanísticas contemporâneas? Como evitar a desordem e a desorganização urbanística, bem como a segregação e a exclusão socioespacial, sem restringir a criatividade social e cultural do fazer e viver a (na) cidade? (Menezes, 2006: 95)

A realidade social, ambiental e cultural das cidades contemporâneas tem requerido visóes sistêmicas e abrangentes, bem como soluçôes inovadoras, cuja elaboração advém de abordagens múltiplas. Assim, por um lado, o projeto visa ampliar a compreensão da complexidade inerente ao exercício da atividade projetual e do papel do arquiteto como agente de transformaçóes sócioespaciais, além de destacar a relevância das interaçóes entre ensino, pesquisa e projeto e entre visôes transdisciplinares. Por outro, busca criar possibilidades de discussão e elaboração de propostas que não apenas aumentem o conhecimento de todos sobre a forma-conteúdo social do bairro, mas que efetivamente introduzam novas ideias ao campo projetual, situadas além das demandas e programas usuais.

Este trabalho apresenta os resultados do processo projetual conduzido nos espaços residuais dos baixios de dois viadutos no Bairro de Laranjeiras entre 2017 e 2019, na cidade do Rio de Janeiro, um projeto-processo que visa incorporar propostas de diferentes grupos sociais desenvolvidas para um espaço público.
A proposta faz parte do projeto de extensão " $A$ Praça, a Rua e o Bairro", que tem buscado desenvolver metodologias participativas e processos colaborativos para projetos urbanos e paisagísticos em recortes espaciais diversos da cidade. Conduzido por docentes e discentes da graduação e da pós-graduação de três universidades, que busca mostrar: (1) a importância da intervenção nas cidades através da participação popular de forma direta na elaboração e implementação de propostas urbanas e paisagísticas; (2) a relevância da aplicação de métodos das ciências sociais para a elaboraçáo de um diagnóstico que compreenda aspectos da cultura, identidade e pertencimento ao lugar. Assim, o projeto buscou efetivar experimentos tendo como objetivo subsidiar o desenvolvimento de metodologias participativas em projetos urbanos; e fomentar o contato e troca entre discentes, docentes e a sociedade, visando a construção de fóruns híbridos de participação, através de um processo de colaboração reunindo os diversos participantes.

As inquietaçóes que foram o ponto de partida para este trabalho originam-se das intervençóes urbanas de caráter rodoviarista, que têm transformado as cidades brasileiras há mais de meio século, priorizando a circulação de veículos individuais. O processo contínuo de inserção de maiores e expressas velocidades e de alargamento das vias, ligado à expansão urbana, mas efetuado não apenas nas áreas de expansão, mas sobre as áreas centrais, introduziu novas escalas urbanas. Alguns dos resultados definem-se pelos inúmeros conflitos entre pedestres e veículos no espaço urbano, além da fragmentação de antigos bairros pré-existentes. Dentro da infraestrutura viária implantada ao longo do século XX, as vias elevadas são 
elementos que causaram fortes impactos, não apenas devido à poluição sonora, visual e do ar, mas também pela segregação e ruptura espacial decorrente da sua inserção nas cidades. Jacobs (1961), Vogel; Mello; Mollica (2017) e Berman (1982), que travam discussões relevantes ao campo do Urbanismo, com críticas à tabula rasa do planejamento urbano de origem modernista e da açáo "renovadora" do Estado, foram motivados pela crítica e contestação às intervençóes nas quais se destacavam a implantação de vias expressas elevadas no interior da cidade tradicional. Assim, a ideia de cidade desenvolvida por estes autores - e que inspira este trabalho - é aquela da unidade do bairro conectada a seus moradores, ao sentido de lugar que reflete as identidades múltiplas da vida urbana, e a uma escala da habitabilidade que se refere à escala do pedestre, daquele que caminha nos espaços públicos do bairro.

Os baixios de viadutos são, em nosso contexto (histórico) de produção urbana, associados a resíduos rodoviários que, apesar da sua desqualificação, poluição e do (aparente) desuso, têm sido ocupados por apropriaçóes diversas, o que passa a configurá-los como espaços potenciais. Porém, os continuados esvaziamentos, degradaçóes e conflitos que se deflagram junto a estes espaços, apontam a demanda por projetos, em diferentes escalas, que mitiguem os efeitos ambientais, e a fragmentação do tecido urbano, favorecendo a fruiçáo dos espaços públicos da cidade pelas pessoas.

A proposta efetuada no recorte espacial dos viadutos de Laranjeiras contou com as parcerias da Associação de Moradores e de coletivos do bairro. Ao longo de dois anos, a equipe buscou suscitar discussóes e propostas de transformação urbana para os dois viadutos, que são espaços-sobra de usos intensos e conflitos conflagrados. Em suma, os membros do Projeto investigaram os viadutos e seus impactos socioespaciais no bairro, conduziram eventos participativos onde propostas e ideias puderam ser coletadas, e a partir disto foram elaborados mapas multiprojetos e propostas para discussão, que serão mostradas mais adiante.

Aqui, resumimos a experiência projetual conduzida para o recorte espacial específico de Laranjeiras em três partes. Primeiro, apresentamos aspectos teóricos e metodológicos da elaboração do processo efetuada pela equipe interdisciplinar $^{2}$. Em seguida, apresentamos a realização dos fóruns híbridos de participação nos baixios dos viadutos, alguns dos resultados obtidos, e as propostas-base desenvolvidas a partir das propostas coletadas de moradores e participantes dos workshops para as discussões públicas: o projeto-processo.

Considera-se que o trabalho tem demonstrado para nós como pode se dar o desenho e construçáo da cidade através de processos participativos e fóruns híbridos de atuação, que tentam incorporar percepçôes e ideias variadas. Para tanto, é importante considerarmos a noção de que há um "saber local, nutrido pelo cotidiano", como propóe Milton Santos (1997: 7).

\section{A construçáo do método}

Como significativamente nos diz Henri Lefebvre sobre a produçáo do espaço: "Cada sociedade (...) produz um espaço, o seu” (1974: 40). Ele propóe então a evidência argumentativa: "O espaço (social) é um produto (social)" (p. 35). Portanto, conhecer o espaço (social) é conhecer o seu processo de produção (social). E a democratização dos processos de produçáo do espaço urbano é crucial 
para a efetiva realização de espaços mais democráticos, que estejam voltados ao interesse comum.

Isto significa que deve haver na esfera pública, uma efetiva democratização da escolha de prioridades na tomada de decisóes, e também na possibilidade de participaçáo nos planos e projetos para a cidade conduzidos pelo corpo técnico. Isto implica na realização de interaçôes diversas, seja no orçamento participativo, na realização de consultas públicas, ou nas discussôes das quais participem técnicos, representantes do poder público e da sociedade civil, moradores, interessados. A participação da população em projetos urbanos vem sendo buscada de modos diversos, mais ou menos inclusivos, por esferas da gestão pública em todo o país, e discutida em diversos foros acadêmicos.

Dentro do campo da arquitetura e urbanismo, há um conjunto de experiências e reflexóes em andamento que buscam compreender o conteúdo social e os valores e significados atribuídos ao espaço. $\mathrm{O}$ projeto de extensão tem buscado a inserção contínua de participantes no desenvolvimento de um projeto urbano. Neste aspecto, introduzir formas mais inclusivas de participação e colaboração é crucial para muitos aspectos dos workshops efetuados. Apreender o processo de colaboração como troca de saberes, técnicos e locais, para a melhoria de espaços, é um dos desafios deste trabalho. Durante os fóruns híbridos de participação buscou-se estimular a percepçáo espacial, convidar ao reconhecimento dos espaços, e imaginar criativamente novas possibilidades para o lugar. Consideramos que, teoricamente, isto é relevante não apenas pela troca de saberes que pode possibilitar, mas pela própria indissociabilidade entre espaço urbano e conteúdo social que é reconhecida por um projeto eficaz. Assim, consideramos que a democracia técnica é um aspecto crucial do campo da arquitetura e urbanismo.

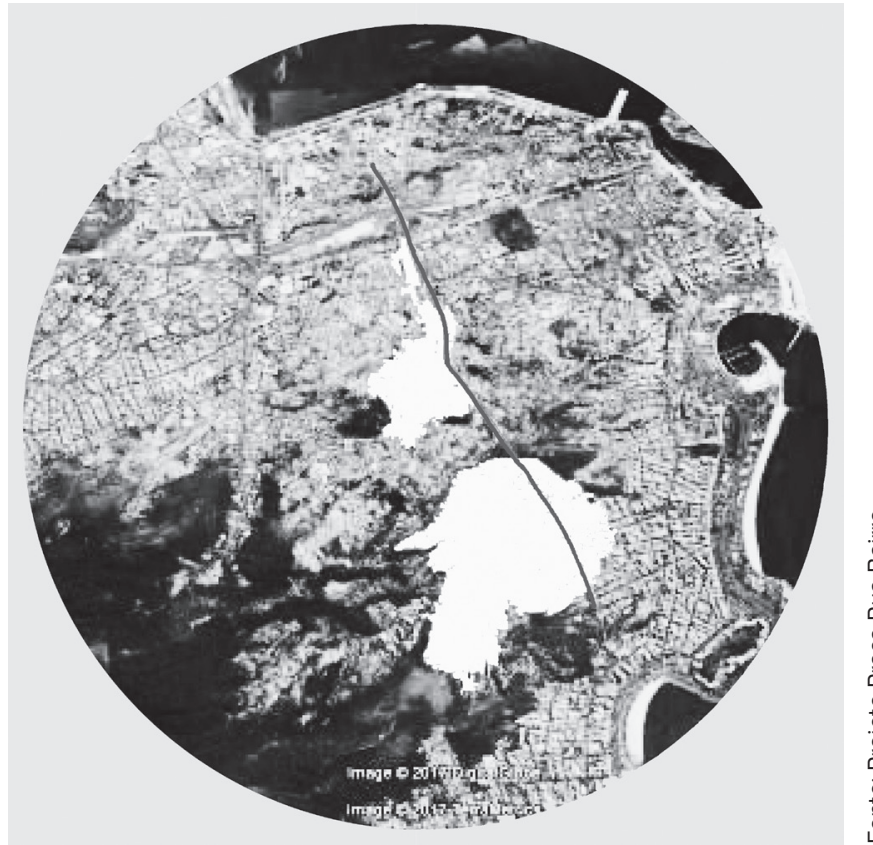

Fig. 01 - Cidade do Rio de Janeiro: a Linha Lilás, unindo os bairros de Laranjeiras e Catumbi, através do Túnel Santa Bárbara.

\section{O projeto de extensáo}

O Projeto de Extensão iniciou-se a partir de dois bairros da cidade, Catumbi e Laranjeiras, nos quais a proposta de renovaçáo urbana e a implantação de viadutos tiveram dois efeitos principais no espaço: a segregação socio-espacial e a presença de sobras rodoviárias ("ilhas de calçada") decorrentes destas intervençôes que priorizaram os veículos individuais.

O projeto partiu, portanto, de uma proposta transdisciplinar fundada na valorização dos espaços públicos na escala do bairro. Dentro do campo da arquitetura, ele se insere em uma busca pela introdução de democracia técnica na elaboração de projetos para a cidade. Para tanto, buscou-se elaborar fóruns híbridos participativos, envolvendo o corpo da universidade com os moradores, 
profissionais egressos e outros grupos sociais interessados, para construir, de forma colaborativa, soluções para a cidade.

Cabe destacar que o bairro do Catumbi é significativo para a história dos movimentos sociais e para os estudos urbanos no Rio de Janeiro e no país. Foi ali que surgiu a pesquisa que originou o livro "Quando a Rua Vira Casa" (com primeira edição em 1985) por Vogel; Mello; Mollica (2017). O livro, que traz uma análise interdisciplinar da apropriação de espaços urbanos do bairro, foi ponto de partida de nossas discussóes, e náo apenas pelo fato de que Marco Antonio da Silva Mello, co-autor da obra, ser participante do projeto. A escolha do caso de Laranjeiras se deu em função dos contatos de parceiros, cabendo lembrar que há uma correlação direta entre Catumbi e Laranjeiras: ambos os bairros foram cortados por viadutos que resultam da intervenção rodoviarista da Linha Lilás, inicialmente proposta pelo Plano Doxiadis, de 1965, e efetuada nos anos 1970 e 1980 na cidade. O nascimento de movimentos associativos nestes bairros está diretamente relacionado com a repercussão destas intervenções.

O projeto nasceu dos encontros de grupos de pesquisa voltados para o Projeto Urbano, Arquitetura da Paisagem, Patrimônio da Cidade, e Etnografia Urbana, em workshops do ensino da graduação realizados em campo, no bairro do Catumbi, em 2016. A experiência do Projeto de Extensão reúne, na Academia, docentes e discentes da FAU-UFRJ, DAU-PUC-Rio, EAU-UFF, GAP-UFF, IFCS-UFRJ, e IPPUR-UFRJ, envolvidos com ensino, extensão e pesquisa em campos diversos e com os coletivos locais e membros de associaçôes de moradores.
Assim, a partir de experiências didáticas anteriores, foi montado um processo participativo a ser efetuado nas áreas urbanas do projeto de extensão. Visava-se assim constituir um ateliê público nos quais os estudos preliminares fossem realizados em paralelo e em conjunto com os moradores, num processo colaborativo no qual o Ateliê registra a memória das propostas e a coerência com outros projetos que se desenvolvem em proximidade. A meta final é constituir um fórum híbrido permanente nos bairros.

\section{A metodologia}

Menezes (2006), ao discutir as dificuldades para a elaboração e concretização de um projeto (social) na cidade, aponta que para ultrapassá-las, duas noções devem ser enfatizadas:

O projeto, entendido como estratégia de invenção/criação de uma nova ordem socioespacial, como expressão cultural, fenomenológica e pragmática; e diagnóstico, concebido num sentido interativo, dinâmico, flexível e com capacidade de articulação disciplinar/ dimensional. Por fim, defende-se a pertinência em seinvestir numa cultura de projeto social da cidade. (ibid: 97) [grifos nossos].

Julgamos relevante enfatizar estas definições, que resumem bem o papel do projeto e do diagnóstico para nossa proposta. Elas apontam para a interação que buscamos construir entre diagnóstico - dinâmico, flexível - e o projeto - invenção, expressão, colaboração - com regressóes e progressóes na elaboração, discussão e avaliação das propostas realizadas para o recorte espacial. 
O trabalho se desenvolve, antes de tudo, com as pesquisas, deambulaçôes e preparação de material de base — plantas, mapas fotos, e maquetes físicas e digitais para apoiar o trabalho de campo e os ateliês públicos.

Em seguida, os membros do Projeto investigaram os viadutos a partir das observaçóes de campo e do percurso etnográfico, conduzindo posteriormente encontros participativos onde propostas e ideias puderam ser coletadas. A partir disto foram realizados mapas multiprojetos e propostas para discussão.

Consideramos que o trabalho efetuado atende ao que Verdier (2009) aponta como as quatro funçôes de sociólogos e interventores sociais na produção do espaço urbano: (1) descritiva, (2) interpretativa, (3) uma função de ajuda à concepção e (4) uma função de gestão e reparadora das ligaçóes sociais.

A participaçáa se dá em três etapas (ver quadro 01). A primeira, de reconhecimento, conta com a realização de diagnóstico rápido participativo. A segunda fomenta proposiçóes efetuadas pelos moradores - apoiados pelos discentes. A terceira consiste nas reflexóes sobre as etapas anteriores e sobre os projetos de discentes já realizados, e também na elaboração de novas propostas agregadoras a partir das anteriores.

$\mathrm{Na}$ parte inicial dos ateliês, o percurso se constituiu tanto em uma aproximação à área pelo público participante, como em um elemento da construçáo do diagnostico participativo da área. Michel de Certeau (1990) nos chama a atenção para a relevância do caminhar, e como esta experiência permite o reconhecimento mais livre do contexto, do entorno. E aponta para a contínua (re) apropriação dos espaços públicos na vida cotidiana, algo que a experiência do caminhar pode demonstrar. Nos workshops realizados com maior duração, executamos dois percursos: (1) a primeira deambulação, à deriva, sem roteiro; (2) o percurso informado, etnográfico, abastecido por informaçóes prévias dos organizadores.
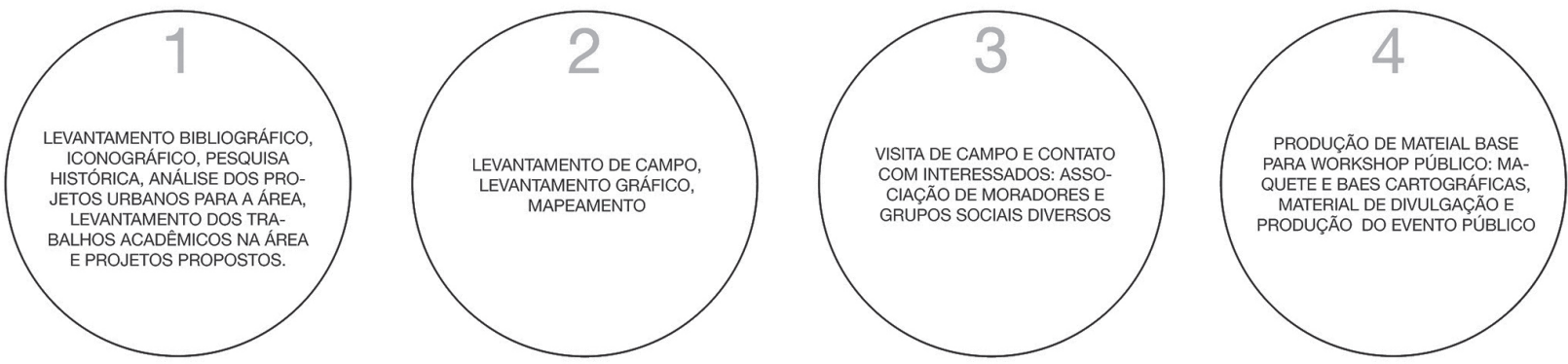

\begin{tabular}{|c|c|c|c|}
\hline & $\begin{array}{l}\text { ETAPA } 1 \\
\text { Descoberta e diagnóstico }\end{array}$ & $\begin{array}{l}\text { ETAPA } 2 \\
\text { Ideias de transformações do } \\
\text { espaço construído }\end{array}$ & $\begin{array}{l}\text { ETAPA } 3 \\
\text { Debate }\end{array}$ \\
\hline $\begin{array}{l}\text { ANÁLISE E } \\
\text { PROPOSTA ESPACIAL }\end{array}$ & $\begin{array}{l}\text { - Introdução } \\
\text { - Deambulações, percursos "guiados", passeios } \\
\text { - Leitura do sítio } \\
\text { - Análises: história, relevo, estrutura fundiária, relações } \\
\text { com o meio ambiente } \\
\text { - Dinâmicas interativas: experimentações }\end{array}$ & $\begin{array}{l}\text { - Proposições de melhorias } \\
\text { - Debates }\end{array}$ & $\begin{array}{l}\text { - Concepção de 'imagens-exemplo' facilmente } \\
\text { legiveis, mas honestas } \\
\text { - Apresentação de vistas localizadas } \\
\text { - Intervenção em Maquete }\end{array}$ \\
\hline $\begin{array}{l}\text { ANÁLISE E } \\
\text { PROPOSTA SOCIAL }\end{array}$ & $\begin{array}{l}\text { - Encontros ocupaçães dos lugares } \\
\text { - Espaços valorizados e desvalorizados } \\
\text { - História social do sítio e do seu ambiente } \\
\text { - Identificação dos atores sociais }\end{array}$ & $\begin{array}{l}\text { - Problemáticas sociais em questão. } \\
\text { - Entrevistas e enquetes. } \\
\text { - Formalização da demanda social } \\
\text { - Exame dos cenários }\end{array}$ & $\begin{array}{l}\text { - Iniciação à linguagem do espaço } \\
\text { - Concertações/acordos sobre a imagem do } \\
\text { conjunto e sobre imagens localizadas } \\
\text { - Concertação/ acordo sobre programas e } \\
\text { gestão dos espacosos e equipamentos públicos }\end{array}$ \\
\hline
\end{tabular}

Quadro 01- Quadro-resumo da Operacionalização dos trabalhos In Situ nos Recortes Espaciais. 
O papel dos percursos é crucial para fomentar propostas projetuais, mesmo nos eventos breves. A equipe registrou o resultado destes percursos, mapear e discutir usos e apropriaçôes, efetivando uma construção continuada do diagnóstico do trecho urbano. Parte desta operacionalização é apontada por Zeisel (1995), que trata de uma investigação através do espaço, e da necessidade de interpretação dos discursos e observaçóes, mostrando que há usos, apropriaçôes e mensagens - adequados, informais, marginais que podem ser observados, ou que são encontrados sob a forma de resquícios de usos — sobras, desgastes - no espaço investigado. Em suma, os espaços são compreendidos pela sua espacialidade, em conjunto com seus usos e apropriaçóes, que permanentemente o reconfiguram:

Nossa visão do espaço privilegia, pois, o aspecto processual e dinâmico. (...) Nesta prática quotidiana está o seu segredo. (...) Praticar o espaço deste ou daquele modo significa conceber a vida social de tal ou qual maneira. As atividades como que escolhem seus lugares, apropriando-se deles, conformando-os às suas exigências, mas ao preço de uma ação de retorno. (...) Os eventos decidem a respeito das próprias qualidades formais do espaço. Produzem, moldam e esculpem os ambientes." (MELLO; VOGEL, 1983)

\section{Os Baixios de Viadutos de Laranjeiras: a cons- trução dos fóruns híbridos de participação}

Os fóruns híbridos de participação foram realizados, no caso dos baixios dos viadutos de Laranjeiras, a partir da organização, produção e divulgação de material de base impresso, digital e físico. As atividades de campo contaram com debates e proposiçôes, diagnósticos rápidos participativos, percursos comentados e palestras, em três tipos de eventos: a) os ateliês públicos, amplamente divulgados, abertos a todos os interessados e realizados no próprio baixio dos viadutos; $\mathrm{b}$ ) os workshops abertos e interdisciplinares que contaram com um público acadêmico interdisciplinar e outros interessados, realizado na sede na AMAL; c) e as atividades estritamente acadêmicas, envolvendo alunos de pós-graduação cursando disciplinas dos mestrados em Projeto de Arquitetura e Arquitetura Paisagística. Nas três ediçóes do evento "Reimaginando os Baixios", conduzido nos espaços públicos dos baixios em 2017 e 2018 foram registradas as propostas de moradores e passantes, através de representaçóes pictóricas, textos e interaçóes com maquetes físicas do espaço (fig. 01). O workshop de projeto interdisciplinar "Repensar os Baixios", em 2018, com a duração de três dias, voltado para estudantes e profissionais ligados à questáo urbana, foi desenvolvido na Sede da Associação e nos espaços do bairro e teve como resultado a produçáo de um vídeo, e de diversos desenhos de propostas projetuais elaboradas pelo grupo de discentes da graduação e pós-graduação em arquitetura e antropologia. Em 2018, foi também efetuado um diagnóstico rápido participativo no recorte, em aula conjunta de disciplinas de dois mestrados- Acadêmico em Arquitetura da PUC- Rio e Profissional em Arquitetura Paisagística, do PROURB- FAU- UFRJ: o evento "Percursos In Situ - uma idéia de cidade". Além das discussôes realizadas, parte dos mestrandos efetuou propostas para os baixios dos viadutos. Em conjunto, estes fóruns híbridos nos forneceram um conjunto diverso de análises e propostas de transformação dos espaços urbanos dos baixios dos viadutos de Laranjeiras. 


\section{O recorte espacial}

Laranjeiras é um bairro relativamente antigo do Rio de Janeiro, na Zona Sul, predominantemente residencial, denso, diverso - contendo moradores de classe média, de alta e baixa renda- e com grande relevância cultural material e imaterial na cidade. Sua ocupação foi iniciada no século XVII, ao longo do vale do Rio Carioca, descendo do Corcovado, da Floresta da Tijuca, à Baía. No século XIX, se tornou uma área nobre, com o surgimento de chácaras rústicas e luxuosas ocupadas por fidalgos e membros da família imperial.
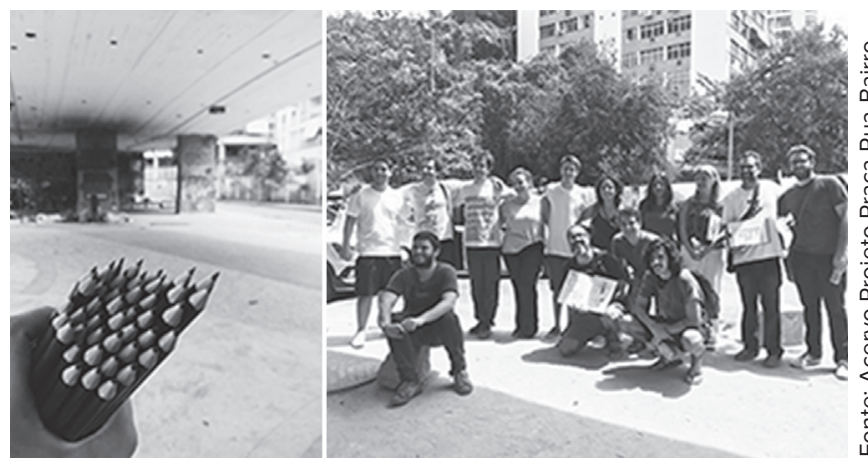

Fig. 02 - Cidade do Rio de Janeiro: a Linha Lilás, unindo os bairros de Laranjeiras e Catumbi, através do Túnel Santa Bárbara.trabalhos In Situ nos Recortes Espaciais.

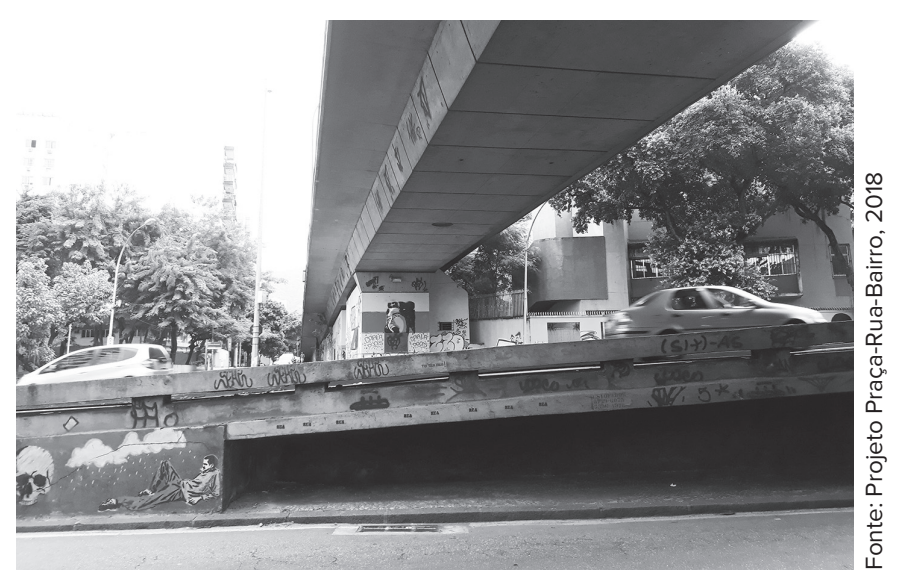

Fig. 03 - O Viaduto Jardel Filho sobre o Viaduto Noronha Santos, na Rua Pinheiro Machado

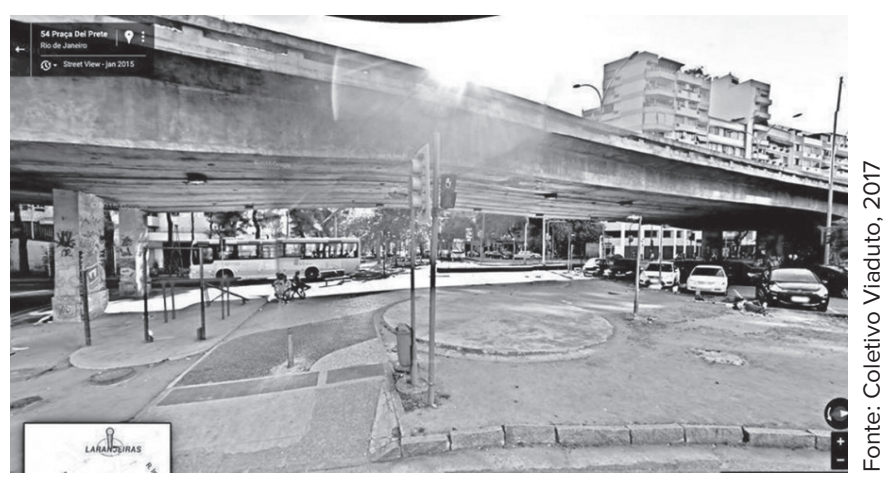

Fig. 04 - O Viaduto Noronha Santos, e parte do projeto paisagístico inicial.

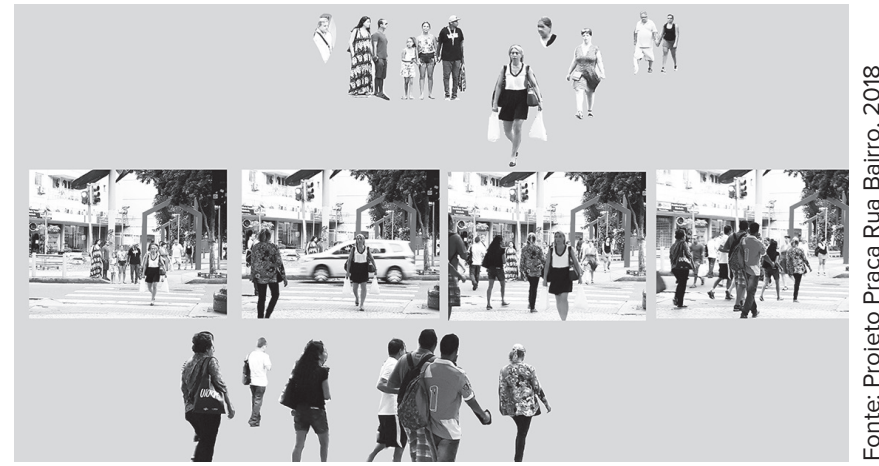

Fig. 05 - Representação sintética do fluxo de pedestres nos dois sentidos de uma das faixas de travessia do Viaduto Noronha Santos. Dia útil, 11 horas da manhã: 18 pessoas.

De 1880 até 1938 , passou a abrigar uma grande fábrica de tecidos, e assim surgiram espaços comerciais e vilas operárias no bairro. A partir dos anos 30, esta fábrica e grande parte das grandes chácaras foram desmembradas em empreendimentos residenciais. Este processo de transformação foi mais lento do que em outros bairros, e ainda restaram casas e jardins originais. Note-se que, no Vale das Laranjeiras, nasceram ou viveram intelectuais e artistas importantes da cultura brasileira, como Lima Barreto e Villa-Lobos, Machado de Assis, Cecília Meirelles, Portinari e Oscar Niemeyer. A partir dos anos 1960, 
porém, obras rodoviaristas realizadas poder público recortaram o bairro, destruindo parte do seu patrimônio arquitetônico, desapropriando moradores e tornando-o um bairro de passagem de intensos fluxos: o Túnel Santa Bárbara (1963), o Viaduto Noronha Santos (1965), o Túnel Rebouças (1965) e posteriormente, no início dos anos 80, o Viaduto Jardel Filho. Por conta deste último, em 1979, foi criada a Associação de Moradores e Amigos de Laranjeiras, a AMAL, que vem lutando pelo bairro e pela preservação do que restou do patrimônio ambiental e arquitetônico, que fica. Com a participação da AMAL, o bairro se tornou também uma Área de Proteção do Ambiente Cultural- APAC.

O trecho do recorte espacial não apenas se constitui em um conjunto de espaços livres públicos fragmentados pelo intenso tráfego de veículos individuais e linhas de transporte coletivo, mas da nova feição que entáo surge em todo bairro, resultante da exploraçáo imobiliária edifícios de classe média standardizados, de baixa qualidade arquitetônica, aumento da população residente, fruto de um processo vertiginoso de verticalização. $\mathrm{O}$ Viaduto Jardel Filho, que cruza a Avenida Pinheiro Machado, atravessa também a rampa de descida do outro viaduto (Noronha Santos), e tem grande parte dos baixios e espaços laterais subutilizados. De um lado, junto a edifícios públicos, há uma arborizada praça de esquina, relativamente vazia (fig. 03). Do outro, já houve uma Cooperativa de Reciclagem sob a sua descida, hoje um espaço gradeado, em desuso. A sede da AMAL se situa deste lado, junto ao cruzamento dos viadutos, com uma quadra de futebol ao lado.

O Viaduto Noronha Santos, que corta a Rua das Laranjeiras e dá acesso à Rua Pinheiro Machado, ocupa uma posição nevrálgica nos fluxos intraurbanos e nos percur- sos cotidianos do bairro. Sob este viaduto Noronha há um largo espaço, que em conjunto com duas áreas fragmentadas de calçadas de quadras dos dois lados recebe a denominação de Praça Del Prete. A área coberta já teve equipamentos e elementos construídos, que se deterioram ou que foram retirados a pedidos, hoje há somente resquícios destes no pavimento (fig. 04). O volume do fluxo de pessoas e veículos é intenso durante todo o dia (fig. 05). Sob este viaduto Noronha há um largo espaço, que em conjunto com duas áreas fragmentadas de calçadas de quadras dos dois lados recebe a denominaçáo de Praça Del Prete. A área coberta já teve equipamentos e elementos construídos, que se deterioram ou que foram retirados a pedidos, hoje há somente resquícios destes no pavimento (fig. 05). Os baixios deste viaduto e seu entorno revelam-se cenários de vários acontecimentos.

No lugar ocorreram, por um lado, inúmeros eventos de violência urbana, e por outro, diversos eventos sociais e culturais importantes para o bairro e sobretudo para aquela regiáo. Há homenagens sob a forma de grafites e de monumento a jovens assassinados ali, e já houve manifestaçôes por segurança pública no local. E há diversos movimentos de retomada do bairro, com mobilizaçóes que conseguiram ciclovias e iluminação pública sob o viaduto, e que doaram bicicletas aos policiais. Além da Amal, o bairro tem outros grupos de mobilização; e há dois diretamente ligados às apropriaçóes sob o viaduto. $\mathrm{O}$ grupo "Laranjeiras Sorri”, criado por moradores "inconformados com a insegurança e a degradação" em 2015, apresentam várias propostas para melhoria e ocupaçáo dos espaços dos viadutos, e promoveu feiras no espaço. "O Ocupa Viaduto", de 2016, tem nos últimos anos organizado eventos com certa regularidade, como as festas juninas, e diversos saraus com microfone aberto sob a 
praça do viaduto, com música, debates e recitais de poesia. Estes eventos remodelam o espaço através de palcos montados, cadeiras moveis, esteiras no chão, revelando possibilidades de uso e permanência.

A presença de ambulantes e camelôs é permanente junto às travessias. E registre-se que, além de catadores e nômades moradores de rua, o viaduto abriga moradores fixos como o catador há mais de uma década, que tem televisão instalada (ANTENORE, 2018).

\section{O reconhecimento e as descobertas}

Os percursos e derivas realizados na primeira etapa dos ateliês públicos e workshops consistiram, antes de tudo, em um momento de descobertas dos espaços dos dois viadutos e seus arredores. Usos e apropriaçôes diversos, inúmeros detalhes formais e funcionais dos espaços públicos, privados e coletivos, mensagens públicas comerciais e pessoais, legais e informais, grafittis e pichaçôes. Ao longo do processo, houve adaptaçôes de uso diversas, como os canteiros delimitados por frutos de coco verde, feitos e mantidos pelo ambulante em bikefood que se instala em certos dias. E o reconhecimento do patrimônio arbóreo e edificado do entorno demonstrou alguns dos valores e significados da cidade e do bairro no trecho percorrido - um anel de quadras no entorno dos viadutos. Neste momento, que antecipa a realização das propostas, os percursos informados e as sucessivas descobertas da equipe foram compartilhadas, bem como os dados da história e da memória do bairro e as narrativas do percurso etnográfico realizado (fig.05). No caso dos dois workshops acadêmicos, estas informaçóes foram completadas por palestras e discussôes na Sede da Amal (fig.06).

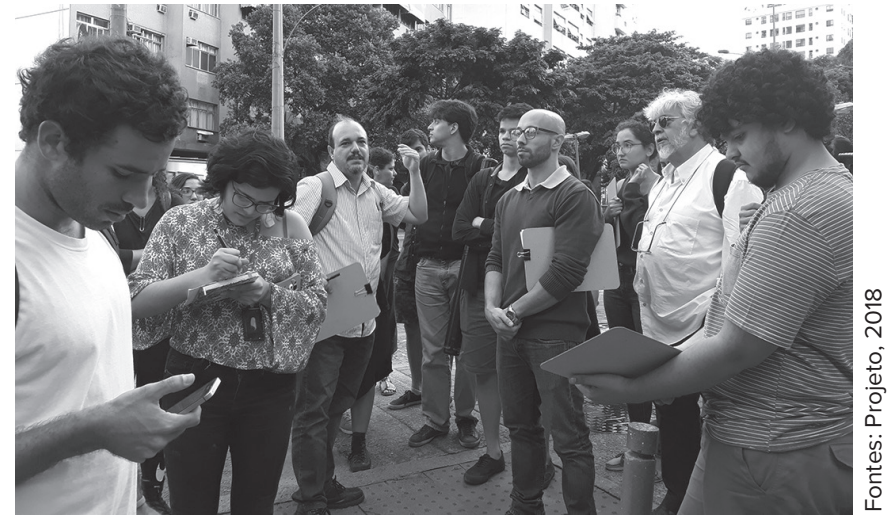

Fig. 06 - Percurso etnográfico e o prof. Felipe Berocan.

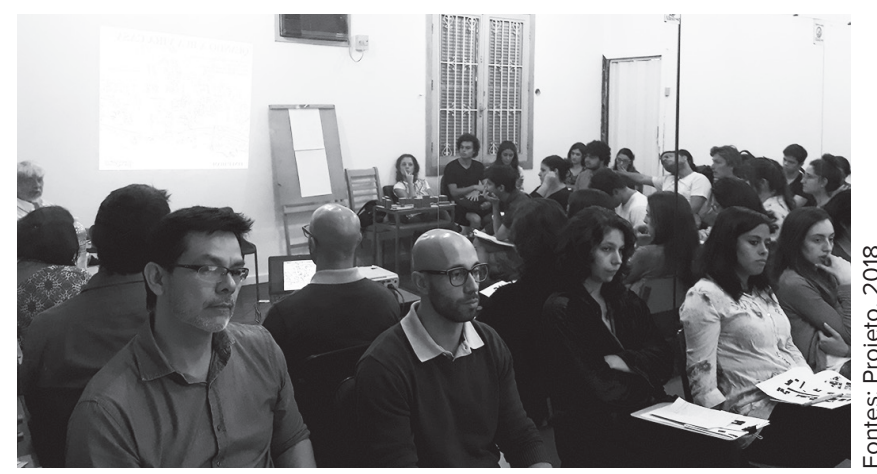

Fig. 07 - Palestra do prof. Marco Mello, na sede da Amal.

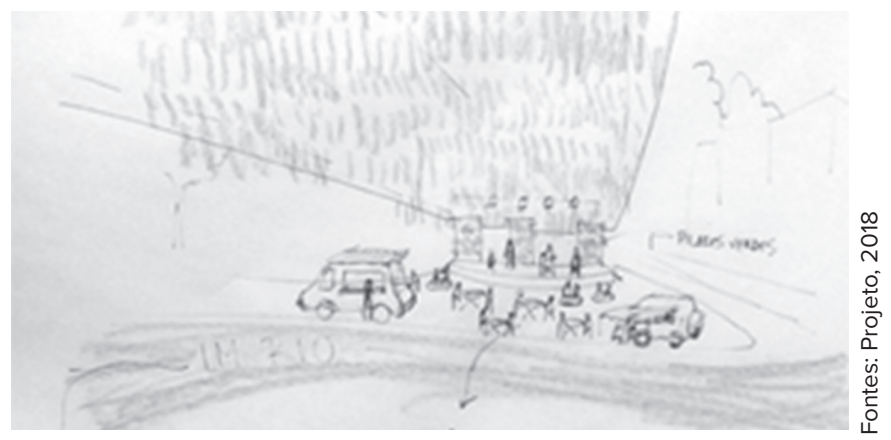

Fig. 08 - Proposta com referência ao Rio Carioca.

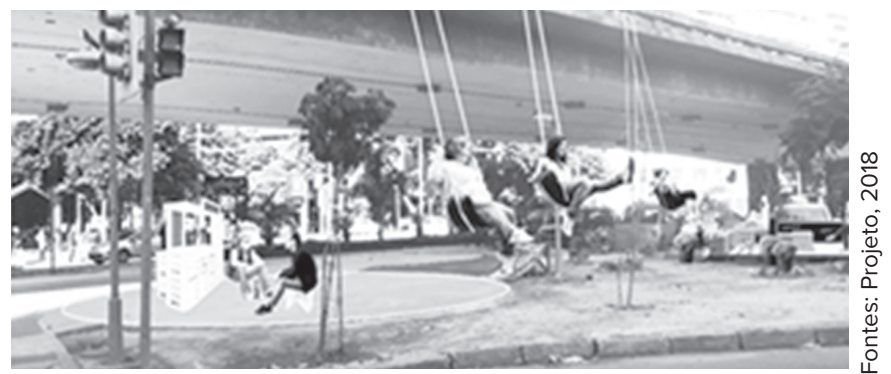

Fig. 09 - Balanços adultos no viaduto. 


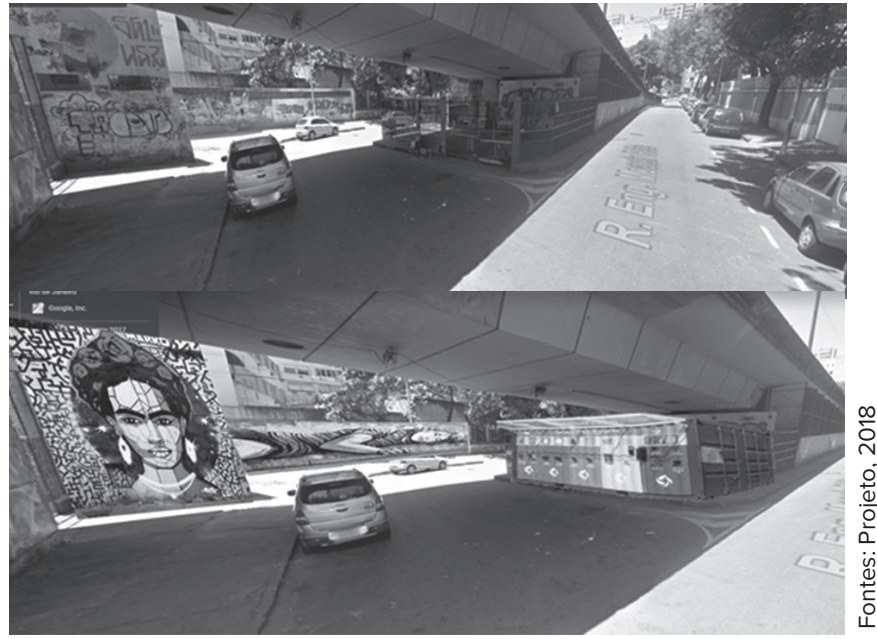

Fig. 10, 11 - Antes/ Depois: proposta leiga desenhada pela equipe do Projeto, de Espaços e Arte / Grafitti nos Baixios.

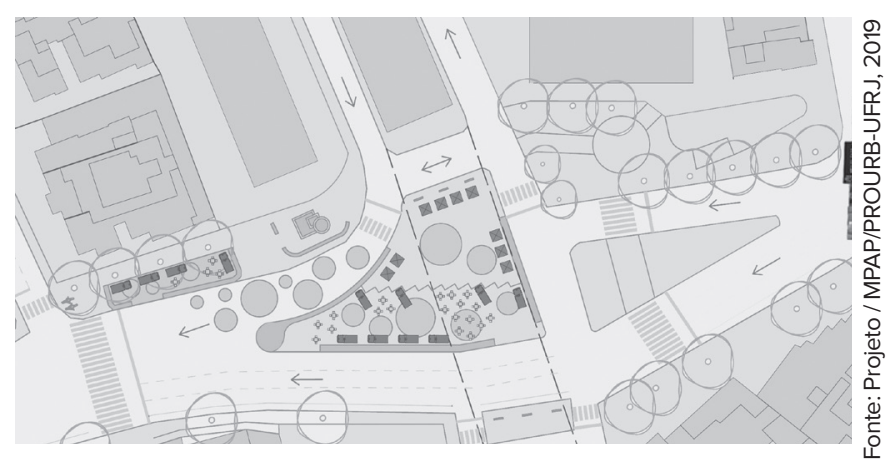

Fig. 12 - Proposta.

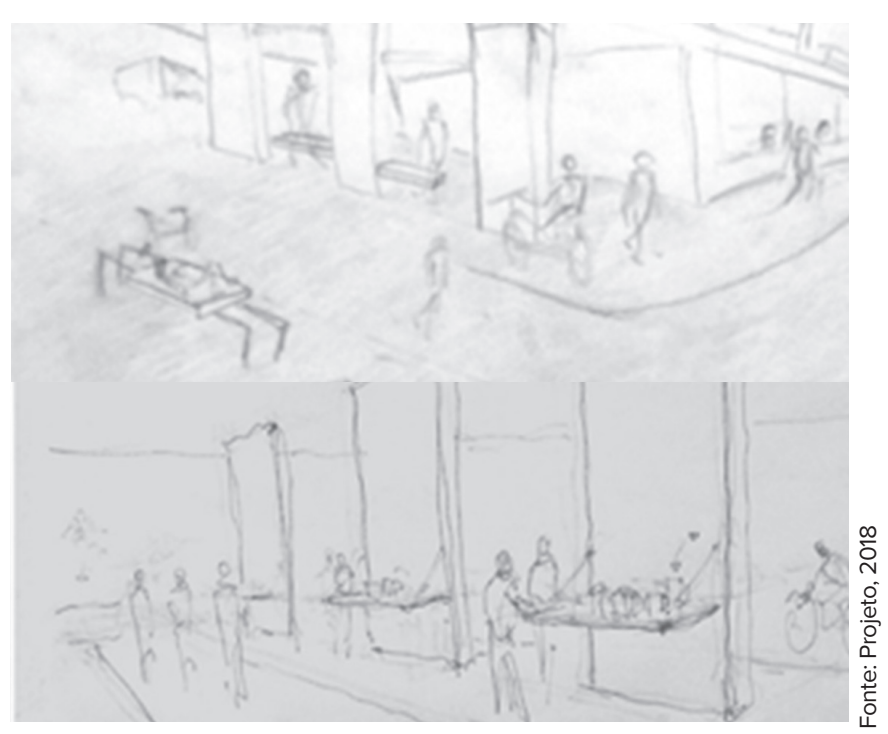

Fig. 12 - Proposta.

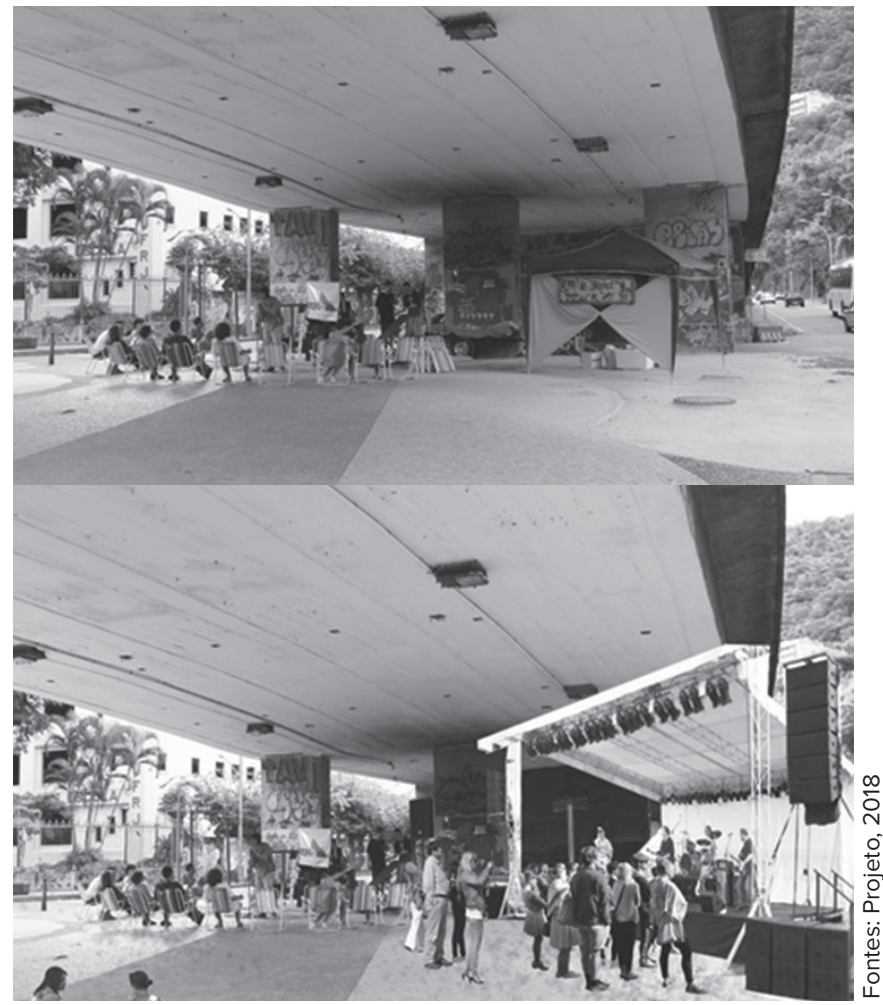

Figs. 15, 16 - Antes/ Depois: proposta leiga desenhada pela equipe do Projeto, de Viaduto Palco nos Baixios.

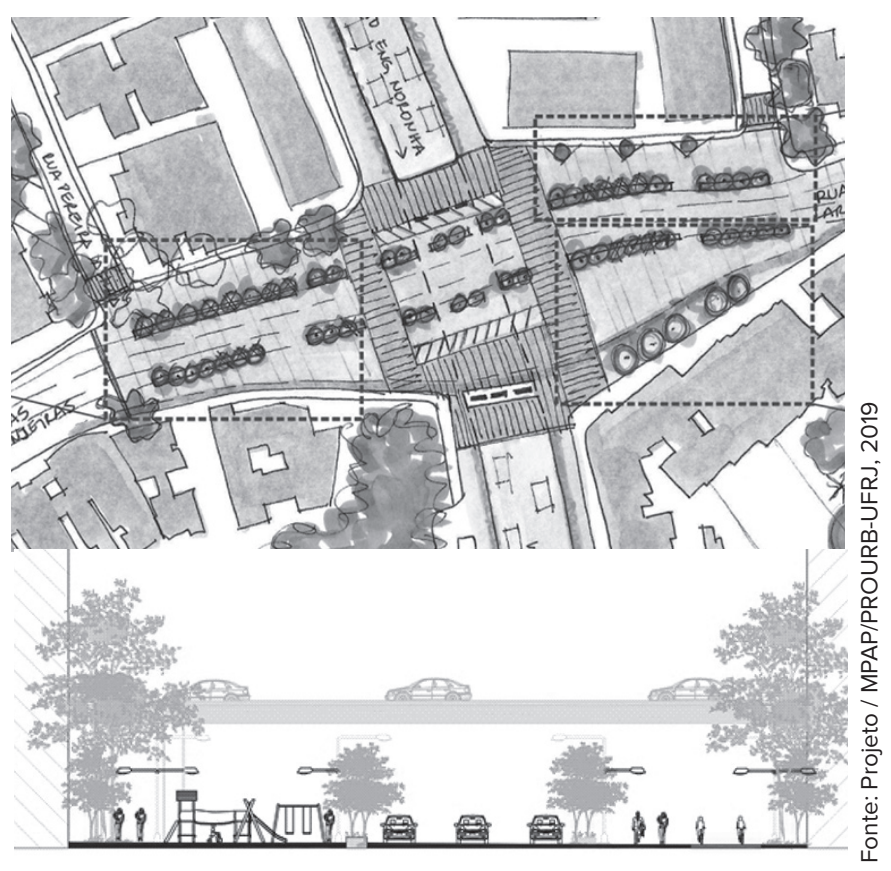

Figs. 17,18 - Passeio Integrado.

Revista online do Departamento de Arquitetura e Urbanismo da Pontifícia Universidade Católica Puc-Rio - Rio de Janeiro Brasil 


\section{As propostas}

A série de propostas para os baixios dos viadutos de Laranjeiras foi coletada em açôes de caráter diverso. Primeiro, nos eventos "Reimaginando", sob os baixios, do qual participaram ao longo do dia discentes e moradores informados pelas redes acadêmicas e do bairro, leigos e arquitetos que desenharam e escreveram suas propostas em material distribuído com apoio de mesa e pranchetas, e interferiram na maquete física. A equipe de arquitetura deu apoio aos moradores, inclusive nas representaçôes de suas propostas. Diversas situaçôes urbanas são notáveis no espaço público, e demonstram seus conflitos e potencialidades.

As diversas propostas coletadas puderam ser identificadas em 6 grupos, por suas escalas de atuação:

(1) Propostas-conceito que representam ou recriam alegoricamente o espaço, com representaçóes diversas, como à água do Rio e ao Teatro (figs. 08 e 09).

(2) Propostas de apropriação por atividades artísticas, que transformem o espaço, , que sugerem espaços de grafitti, exposições (fig. 10 e 11).

(3) Propostas de cunho temporário, como aulas e eventos sob os baixios, elementos flexíveis, parque aberto ou parklets (figs. 12, 13 e 14 ).

(4) Propostas de plantio, com a vegetação como elemento decorativo- recobrindo estruturas em concreto ou elemento produtivo, como a de um Circuito Verde áreas de plantio produtivo, que dependem de manejo e engajamento.

(5) Propostas em pequena escala, de mobiliário urbano, atendendo aos eventos culturais e festas na Praça do
Baixio Eng. Noronha Santos - repensando as áreas de palco, público e passagem, proporcionando assentos; e a alocação de atividades comerciais sob o viaduto e nos arredores (fig.15 e 16).

(6) Propostas pedonais, voltadas para a modificação dos percursos de pedestres no arquipélago de sobras rodoviárias, com novas faixas, fechamentos de trechos, levantamento do piso e redução das velocidade (fig. 17 e 18).

(7) Propostas radicais, com a supressão de viadutos, demonstrando como seria o espaço sem os viadutos. Uma delas transforma o viaduto em pistas subterrâneas, sob o Rio Carioca, com a volta ao nível térreo mais adiante.

\section{O Projeto Processo}

Por fim, na última e mais recente etapa, a partir da organização dos registros múltiplos coletados, a equipe partiu para a elaboração de um projeto-processo próprio, contendo mais de uma proposta. Considera-se que a presença de projeto informado e congregador pode ser o ambiente ideal de debate para que se forje um processo decisório pleno. Esta contribuição visa fomentar, a partir de novos fóruns híbridos a serem realizados, soluçóes mais justas e adequadas para a circulação, apropriação e fruiçôes dos baixios de viadutos em Laranjeiras, que carecem de boas intervençôes públicas em diferentes intensidades e escalas.

Estas propostas não são consideradas findadas. São, antes de tudo, caminhos que podem conduzir a ações mais imediatas ou, na melhor das hipóteses, à informação para alimentar editais de concursos para a área. Consideramos que o mais importante 
é a trajetória que imprime, às reflexóes da esfera pública sobre os espaços, seus usos e apropriações.

\section{Conclusão: os desafios da pesquisa-projeto-intervençáo}

Construir a cidade é tarefa que resulta das obras infraestruturais, dos projetos urbanos, das construçôes de equipamentos públicos, das relaçóes que os edifícios estabelecem com as ruas, e também de como as pessoas usam e se apropriam dos espaços da cidade.

Frequentemente, porém, há uma desassociação entre as propostas urbanas executadas, e o contexto urbano e social dos lugares em questão. Isto se dá nas grandes intervençôes urbanas e projetos urbanos que espetacularizam a cidade, que respondem a demandas alheias ao lugar em que interferem e transformam. Mas também pode ser observado em nos projetos "menores", sobre a criação e reforma dos espaços públicos, equipamentos, sobre a concessão de usos em áreas públicas, na alocação de recursos e nas "pequenas" decisóes da gestão.

Quando a população é convocada a participar, espera-se que ela leve suas demandas, ou que tenha contato com proposta técnica já elaborada e considerada previamente pelos gestores públicos - o que pode ser considerado participação. A sua inserção em todas as etapas do processo projetual - o que pode ser compreendido como colaboração — demandaria maior elaboração, interesse político, abertura técnica, o que nem sempre é livre de conflitos e desejado pelos que decidem.

Exemplos recentes apontam a ausência de participação da população nas decisões sobre as cidades. Observe-se que as operaçóes urbanas foram parcerias público-privadas estabelecidas pelo Estatuto da Cidade como instrumentos para uma conjunção de esforços em intervençôes por melhorias urbanas. Porém, em diversos casos pelo país, se tornaram decisóes de grande escala financeira, sem participação efetiva, atropelando planos locais embasados e outras pré-existências. Como no caso do Porto Maravilha, no Rio de Janeiro, discutido por Barandier, "uma operaçáo que privilegia o arranjo financeiro e a criação de oportunidades para o mercado, em detrimento do projeto como elemento estruturador do processo de transformaçấo da área de intervenção" (2015, p. 174). No Porto do Rio, não apenas o processo, mas as escolhas da intervenção entraram em conflito com o saber acumulado pelo campo da arquitetura, urbanismo e paisagismo em relação a áreas centrais desfuncionalizadas.

A opção pela linha da renovaçáo urbana e das grandes obras, apesar do discurso de revitalização e valorização do patrimônio cultural, provoca, desde os primeiros momentos, reaçóes de diversos setores dos movimentos sociais, de organizaçóes profissionais e da academia por diversas razóes. Trata-se, na verdade, de um projeto urbano sem adesão social. (loc.cit.)

Enquanto isso, nas ruas e nas redes, associações de moradores e outros grupos sociais realizam críticas e debates sobre problemas urbanos, intervençóes e omissōes do poder público e seus impactos no cotidiano.

Há uma conjunção de interesses possível na construção da cidade, em algumas de suas escalas? A proposta de fóruns híbridos participativos começa pela escala do bairro, e pela tentativa de estabelecer um diálogo projetual entre academia e sociedade - poder público, moradores, coletivos e outros grupos. Neste processo, cada um destes grupos tem desafios a vencer.

Os técnicos de atuação pública ou privada partem da compreensão de que toda técnica aplicada na cidade é 
política, não só pelo grau de participação que ocorre na sua efetivaçáo, mas no próprio processo interno, nas decisões de projeto, que traçam escolhas sociais e culturais. Partem também do entendimento de que a autonomia do projeto é justificável quando possibilita a criação e inovação do arquiteto, mas a heteronomia pode abrir o projeto para discussão de soluçóes compartilhadas, por outros técnicos, e principalmente por aqueles que irão utilizar e se apropriar do espaço. Para as soluçóes em pontos de alta vulnerabilidade social e ambiental, isto é crucial, pois há maior complexidade no processo e na manutenção futura. Não é sem esforço que se tem menos autoria e mais engajamento.

Para os moradores da cidade, o desafio da participação está no tempo extra de se pensar e discutir com paciência o que possível e viável para o seu próprio habitat. Muitos moradores de espaços urbanos têm propostas para suas ruas, calçadas e bairros, lugares das suas vivências como pedestres, usuários, motoristas e passageiros. Fomentar a organizaçáo e o aumento desta participaçáo faz parte de um processo de educação urbana. Neste, a coisa pública pode ser entendida, não como de ninguém, mas como sendo de todos.

Enquanto isso, na academia, pesquisa-se e discute-se as grandes questóes do urbanismo, os resultados e potencialidades de algumas das situaçôes e açôes nas cidades. $\mathrm{E}$ as escolas de arquitetura e urbanismo, desenvolvem inúmeros projetos, especialmente em relação aos grandes centros urbanos. Nestas propostas, em diversas escalas, podem ser encontradas boas ideias e soluçóes urbanas que merecem o debate, mas nem sempre sáo publicamente discutidas.
A possibilidade de que a junção de cada uma destas propostas- profissionais, públicas e acadêmicas, construa um processo de elaboração mais lento, é o que os fóruns híbridos de participação buscam fomentar. Lembremos que não são apenas as grandes obras, mas as pequenas intervençôes, permanentes ou temporárias, na arte e nos usos e apropriaçôes, que definem a construção de uma cidade. Por fim, nos parece ser importante que um bom projeto apresente registros da história e memória que demostrem a sua idealização, pré-existências, informações qualitativas e quantitativas que o forjaram, e as discussôes, obstáculos e possibilidades, àqueles que efetivamente o desenham e vivenciam.

É neste processo, que visa a qualidade urbana, e para o qual a academia possui ferramentas de contribuição para a elaboração técnica e apoio na interlocução entre os agentes sociais, que se insere o projeto de extensão "Praça-Rua-Bairro".

\section{Notas de fim:}

1. Este artigo baseia-se no trabalho apresentado e discutido no $21^{\circ}$ Congresso Brasileiro de Arquitetos, realizado em agosto de 2019, na cidade de Porto Alegre - R.S.

2. Equipe formada, além das professoras co-autoras deste artigo, pelos professores e pesquisadores Felipe Berocan Veiga (PPGA-UFF), Marco Antonio da Silva Mello (PPGA-UFF), Leticia de Luna Freire (FEBF-UERJ), Soraya Silveira Simóes (IPPUR-UFRJ), Cristóvão Duarte (MPAP-PROURB-UFRJ) e Victor Andrade Duarte (MPAP-PROURB-UFRJ) Este trabalho foi efetuado com o apoio dos parceiros, e em parte do período, com bolsa PROFAEX da UFRJ, 


\section{Referências Bibliográficas}

ANTENORE, Armando. Próximos Capitulos: Um semteto à espera da tevê digital. Revista Piauí. Rio de Janeiro: Revista Piauí, janeiro 2018, Edição 136. In: https://piaui. folha.uol.com.br/materia/proximos-capitulos/\#

BERMAN, M. Tudo que é sólido desmancha no ar. São Paulo. Cia das Letras, 1986.

CERTEAU, Michel de. A invenção do cotidiano: 1, Artes de fazer. Petrópolis: Vozes, 1994, pp. 169-191 [1980].

JACOBS, Jane. Morte e vida de grandes cidades. São Paulo: Martins Fontes, 2000 [1961].

LEFEBVRE, Henri. La Production de l'Espace. Paris: Éditions Anthropos, 3eme édition, 1986 [1974].

MELLO, M. A. S.; VOGEL, A. Liçôes da Rua: O Que um Racionalista Pode Aprender no Catumbi. Arquitetura Revista FAU UFRJ. Rio de Janeiro: 1983 v. 1, n.1, pp. 67-79.

MENEZES, Marluci. "Contributos (Antropo) Metodológicos para um Projecto Social de Cidade". Porto Alegre: Revista de Ciências Sociais da Unisinos, 2006, v. 42, n. 2, pp. 94-104.

SANTOS, Milton. O território e o saber local: algumas categorias de análise. Rio de Janeiro: Cadernos IPPUR, v. 13. Rio de Janeiro: n. 2, 1999.

VERDIER, Philippe. Le projet urbain participative apprendre à faire la ville avec ses habitants. Adels/Yves Michel. Paris: Collection Société civile, 2009.

VOGEL, Arno; MELLO, Marco Antonio da Silva; MOLLICA, Orlando. Quando a rua vira casa: a apropriação de espaços de uso coletivo em um centro de bairro. 4a . ed. rev. e aum. Niterói: EDUFF, 2017 [1980].

ZEISEL, John. Inquiry by Design: Tools for EnvironmentBehavior Research. Cambridge (MA): Cambridge University Press, 1981 [1995]. 